\title{
THE EVALUATION OF THE CONTENT OF FIBERS IN STEEL FIBER REINFORCED STRUCTURES AND IMAGE ANALYSIS
}

\author{
Marek ĎUBEK $K^{*}$ Peter MAKÝŠ, Silvia ĎUBEK, Marek PETRO \\ Department of Building Technology, Faculty of Civil Engineering, Slovak University of Technology in Bratislava, \\ Radlinského street 11, 810 05, Bratislava, Slovakia
}

Received 27 November 2017; accepted 07 March 2018

\begin{abstract}
The distribution of fiber orientation is an important factor in determining the mechanical properties of fiberreinforced concrete. This study proposes a new image analysis technique for improving the evaluation accuracy of fiber orientation distribution in the sectional image of fibers reinforced concrete. The article is devoted to research the systematic evaluation of fiber-cuts through the image processing software. Mathematical representation of the final dispersal of fibers in steel fiber-reinforced concrete is incorporated into a programmed evaluation software. The software detects fibers and classified according to their axes of rotation angle and size of the identified ellipse detection area. Image processing algorithm and detecting fibers has been developed only for these research purposes. Detection area is randomly inserted via steel fiber reinforced concrete structure. The results show the average value of uniformity in the fiber-samples produced in the laboratory.
\end{abstract}

Keywords: fiber reinforced concrete, dispersion, uniformity, digital photography, image processing, beams.

\section{Introduction}

"SFRC" fiber reinforced concrete is a composite material with higher strength characteristics. Thus, the distribution of fibers strongly influences the resulting mechanical performance of the composite (Dupont, Vandewalle 2005; Kwon et al. 2012; Tosun-Felekoğlu et al. 2014; Ferrara, Meda 2006; Katzer, Domski 2012; Gregorová, Štefunková 2016; Leone et al. 2018; Lee et al. 2017). Short fibers with lengths of 6 to $40 \mathrm{~mm}$, which are randomly distributed in all directions, so as to have isotropic behavior, are commonly used in fiber-reinforced concrete. However, the real fiber distribution is strongly influenced by various factors, such as the fiber characteristics, including the diameter, length and volume fraction, the rheological properties of the matrix, the placing method, the shape of the form, etc. Non-uniform fiber distribution decreases the effect of fibers on strengthening the matrix (Mobasher et al. 1990; Poitou et al. 2001). The basic requirement for full effect of fiber in SFRC is uniform fiber dispersion, called homogeneity. Effectiveness of fibres greatly depends on their orientation in respect to geometry and load direction, and they tend to orient during casting (Grunewald et al. 2003; Ponikiewski et al. 2015; Martinie, Roussel 2011; Şanal, Ozyurt 2013) and this tendency has been in- vestigated by many authors (e.g. Gettu et al. 2005; Stähli, van Mier 2007; Stroeven, Guo 2008). The knowledge and understanding of this behaviour can be used to optimize the casting process to orient fibres in the desired direction. Numerical simulation is increasingly being used to model the flow behaviour of concrete (Roussel et al. 2007; Deeb et al. 2014), including fibres reinforced concrete (Kang et al. 2011). There are several types of techniques that are widely used to determine fibers distribution in cement-based materials. One is the image analysis of cross-section of specimen which includes cutting samples and acquiring image by an optical microscope. It is one typical destructive measurement and needs a long time for preparing samples (Wang et al. 2017; Ponikiewski, Gołaszewski 2015). As a non-destructive, efficient and high-resolution method, X-ray CT imaging technology is an applicable method for investigating the internal microstructure of cement concrete with three-dimensional "3D" view (Henry et al. 2014; Wang et al. 2018; Ponikiewski, Gołaszewski 2015; Liu et al. 2013; Balázs et al. 2017; Kim et al. 2012; Ponikiewski et al. 2015; Wong, Chau 2005; Komárková 2016; Yang et al. 2013; Mishurova et al. 2018). As an alternative the magnetic method is being developed

${ }^{*}$ Corresponding author. E-mail: marek.dubek@stuba.sk 


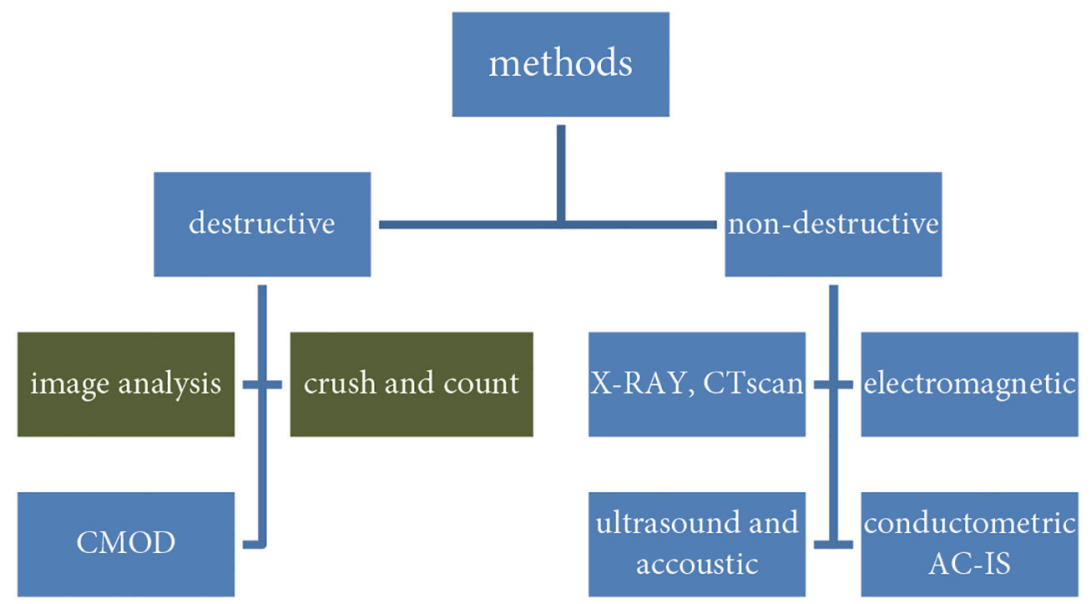

Figure 1. Fiber distribution and (or) orientation methods

by Italian (Ferrara et al. 2012) and Spanish (The fib Model Code... 2013) research groups as well as another (Nunes et al. 2016, 2017). Among the various techniques, image analysis provides direct information on fiber dispersion and orientation. However, previous studies reported that a two-dimensional image analysis technique may induce a significant systematic error in orientation measurements according to image resolution (Eik, Herrmann 2012; Eberhardt et al. 2001). However, these methods, whether direct or indirect, destructive or non-destructive, are not easily applied to built structures (Figure 1). Therefore, we present a new image analysis technique to improve the evaluation accuracy of fiber orientation distribution in the sectional image of fiber-reinforced cement-based material. The proposed image analysis technique estimates the distribution of fiber orientation from the number of fibers in the sectional images because the number of fibers is dependent on the distribution of the fiber orientation.

\section{Research a methodology}

\subsection{Methodology}

Experimental beams. For research purposes and to verify dispersion ratings of the reinforcement, beam samples with dimensions of $150 \times 150 \times 550 \mathrm{~mm}$ have been produced (see Figure 1). The beams were cut into smaller parts with dimensions of $100 \mathrm{~mm}$. The cut surfaces of the fiber-reinforced concrete beams $(150 \times 150 \times 100 \mathrm{~mm})$ were photographed and analyzed with the help of a software.

The developed software was supposed to identify the number of fibers, their direction and spatial orientation taken from the images of fiber-reinforced sample cuts.

Core drills. Comparison and verification of the fiber spatial orientation of the produced structure were conducted on the SFRC structure's core sample. The experimental samples were obtained via core drilling.

Materials used. Mixed Portland cement CEM II / B-M (S-V-LL) $32.5 \mathrm{R}$, mined aggregate and steel fibers $60 \mathrm{~mm}$ long and $1 \mathrm{~mm}$ in diameter were used to produce the six fiber-concrete samples (beams). As for the concrete pro- duction, a fresh reference concrete formula was used, according to EN 14845:2007 (2007) with water cement ratio of 0.55 . The cement dose amounted to $320 \mathrm{~kg} / \mathrm{m}^{3}$, water batch $176 \mathrm{~kg} / \mathrm{m}^{3}$, aggregate fractions $0 / 4 \mathrm{~mm}$ and $8 / 16 \mathrm{~mm}$ aggregate fractions were loaded both with $952 \mathrm{~kg} / \mathrm{m}^{3}$. The dosage of the fibers was determined according to the draft for floor structures $-30 \mathrm{~kg} / \mathrm{m}^{3}$.

The fibers used in the experimental beam sample production were selected with respect to its dimensions and were identical with the fibers used to produce the SFRC structure (Svoboda, Doležal 2008). The direction of detected fibers is dependent upon the indicative factor of the structure and therefore the dimensional characteristics of the beams crucial to the choice of the fiber's length. The orientation factor has been the subject of the research (Gettu et al. 2005; Lee et al. 2009) and indicates the direction and position of the fibers at the edges of the sample. The casting walls have a big impact on the direction of the fibers and therefore the indicative factor is in the element's middle $\alpha_{1}=0.5, \alpha_{2}=0.6$ and at the edges $\alpha_{3}=0.84$. Depending on the shape of the casting the " $\alpha$ " is calculated as a total. The fibers were thus selected with a length of $60 \mathrm{~mm}$ and a diameter of $1.06 \mathrm{~mm}$. Their slenderness ratio equals to 55 . Slenderness ratio characterizes the shape of the fiber and determines the ratio of fiber length to its thickness. The same formula was used in the concrete implementation of SFRC floors in industrial buildings.

Cutting samples and photography. The cutting of experimental beam samples was conducted on a bench saw with a high speed cutting disc.

The beam has been slid on a sliding table (runner) at an appropriate speed so that the fibers on the surface of the cut would not have been deformed (Eik 2014). Diamonds on the cutting disc could damage the surface of the transected fiber, which may result in lower light reflection during photography. This may cause an incomplete loading of fibers by the developed software. In the case of damaged fibers, the surface of the cut may additionally be sanded, achieving a straight cut surface of the fibers. 


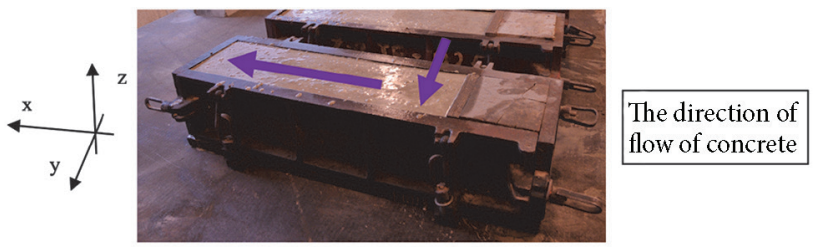

Figure 2. T Production of samples

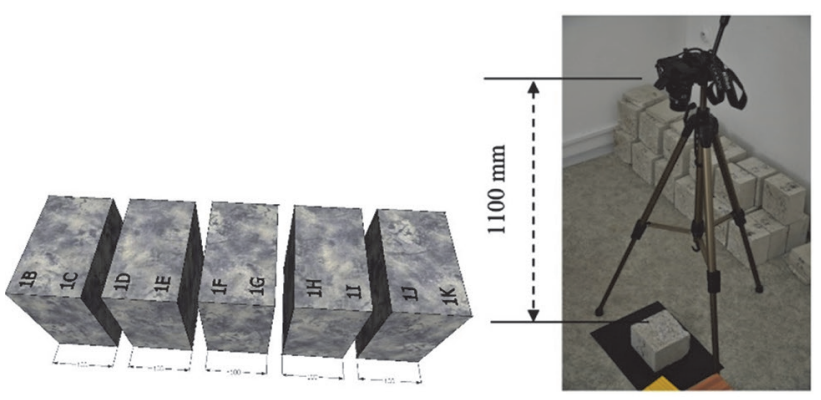

Figure 3. Imaging method

The images would then visualize all transected fibers, which are located in the cross section of the beam. Diagram showing the section in Figure 2.

The camera was placed on a tripod to achieve higher image quality during imaging (see Figure 3). Additional flash has not been used during imaging, so the software is also able to process the reflection of natural light from the fibers. Shiny surfaces of the cut fibers with higher reflectivity than concrete reflected more light. Thus, they appear on images as bright areas (areas with high brightness). Imaging is conducted on all surface cuts. The cut surfaces have not been additionally treated.

\subsection{Research of expression of dispersal}

A homogeneous fiber reinforced concrete should contain homogeneously dispersed fibers. Random distractions should constitute fibers rotated around each axis in space. The subject of this research is fiber dispersion in the hardened fiber reinforced concrete. Frequency is used to express the number of fibers per unit area (Ponikiewski, Gołaszewski 2015; Balázs et al. 2017). To illustrate the ran- domness of dispersed fibers, see Figure 4. It also illustrates the core drill method as well as the detection area.

Spatial distribution of fibers. Fibers in the concrete are arranged randomly. Spatial location and orientation are also affected by the materials used. Fiber position in space (Zhu et al. 1997) can be determined through magnetic induction, or X-ray radiation (Rudzki et al. 2013; Ponikiewski, Golaszewski 2012; Balázs et al. 2017). The direction of the fibers, as well as its position is affected by several factors. The direction of flow and filling of the concrete has a significant impact on the direction of the fibers (Stähli 2008; Ferrara et al. 2008; Švec et al. 2014) in the hardened fiber reinforced concrete. Management of fiber distribution and direction has an effect, e.g. on the production of prefabricated concrete elements (Špak et al. 2016), where the direction of acting force is a known factor.

Figure 4 indicates a randomly inserted surface in a space. Randomly transected fibers are shown on the cut's surface, drawn in the shape of a circle or ellipse. Cuts subjected to photo shootings constitute such random surface inserted into the space.

Inclination of the transected fiber and its shape - the size has already been the subject of research (Yong-zhi 2000; Stroeven, Guo 2008). The size of the ellipse, used as an expression of the fiber's direction randomly passing an inserted surface, has been expressed for the software's purposes as the ratio of the two axes of the ellipse.

It was this research's priority to programmatically identify the diameter of the transected fibers. The fibers will then be assigned by the software to the axis based on the dominant angle.

If the length of one axis of the ellipse is greater than 1.311 times the dimension of the shorter diameter of the fiber expressed in pixels, it is associated with an axis " $\mathrm{z}$ " or " $y$ ". This multiple is expressed by a plane intersecting the fiber by less than 45 degrees. In case the fiber is identified with a smaller aspect ratio or annular diameter, it is assigned to the " $\mathrm{x}$ " axis. Based on the rotation angle of the long axis of the ellipse " $\beta$ " of the identified fiber, the software assigns the fiber to " $z$ " or " $y$ " axis. Rotation higher or lower than 45 degrees is critical (Žirgulis et al. 2016; Eberhardt et al. 2001; Eik 2014; Balázs et al. 2017).

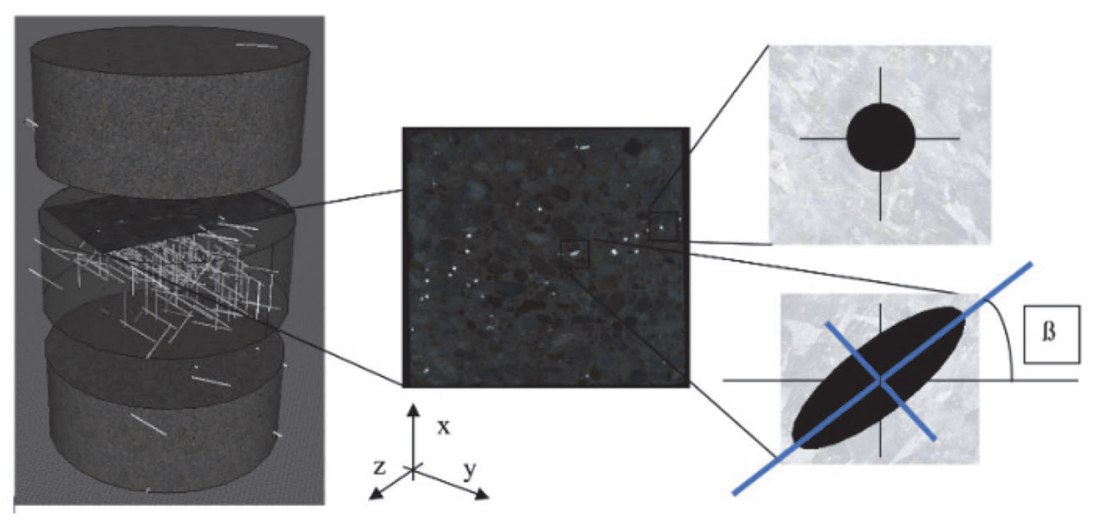

Figure 4. Randomly inserted surface into a space - a model 
Dispersion of fiber in space. The number of randomly transected fibers arises from the likelihood of fiber found in a cross-section of the volume. It's based on fiber dimensions and calculations with respect to $1 \mathrm{~m}^{3}$ of concrete. Stereology and morphometry addresses the visor display (3D) using 2D (area) image projection. It means a spatial interpretation of the two-dimensional image, based on probability and statistics.It can express the number of pixels per unit of the volume or spatial orientation, point density or bulk density of the structure. Fiber properties and their dimensions are identifiable.

Assuming the amount of the detected - exposed fibers we therefore base our assumption on the dimensions and entrainment of the fibers and definitions of the III. stereology sentence, that reflects the median value of random intersections and reads as follows.

Each cubic meter of infinite space contains $L$ meters of flexible fibers. If we place an area of 1 square meter in the space, then the median number of intersections of fibers with an area "s" is calculated as (Stroeven, Guo 2008; Barbier 1860):

$$
E(N)=\frac{L . s}{2}
$$

where: $E(N)$ - the median number of cross points (pc); $L$ - length of the fiber in total (m); $s$ - area embedded in a space randomly.

The fiber diameter and its cross-sectional area is at the size of the fibers of the stereological calculation negligible. The priority is to know the length of the fiber and their quantity in the monitored volume. In 3D space each cutting surface should portray fibers representing the direction around each axis equally. The same percentage representation proves homogeneity of the fibers. Fibers perpendicular to the direction of the cut, " $x$ " axis, will render a circle. Fibers rotated parallel to the axis " $y$ " and " $z$ " are drawn as an ellipse (Stähli 2008). In the cross section in Figure 4, the fibers are drawn as circles or ellipses. The fibers on the cross section of the fiber reinforced concrete are arranged according to their position and direction. It proved necessary to identify and express this arrangement. To express the fiber arrangement on the cutting surface, the distribution coefficient at has been used (Lee et al. 2009). It is based on the number of identifying fibers and their conversion into an area divided into tabs according to the number of fibers. We get an identical result with a similar algorithm of the expressed uniformity index uniformity of I.st order. It is the number and size of the individual squares assigned to the fibers according to the direction and count of the fibers identified by the software (Kang, Kim 2012; Ponikiewski, Gołaszewski 2015). Figure 5 shows 40 identified fibers. The cross-sectional area (sample dimensions $150 \mathrm{~mm} \times 150 \mathrm{~mm}$ ) has to be divided by the number of fibers found for each axis - based on the image we're dealing with 40 pieces. Together, along the axis " $x$ " 32 fibers, 7 fibers along " $y$ " and a single fiber along axis " $\mathrm{z}$ ". The length of the associated squares " $a$ " is then the square root of that value for each axis. Since the fibers arranged in the cross section are random, each fiber is assigned to a square of dimensions "a" time "a" according to the area of the cut sample divided by the number of fibers for each direction (being the 32, 7, and $1 \mathrm{pc}$ ). Their overlapping reduces the sum of the overlapping area to the total cross-sectional area. After subsequent partitioning of this area $P_{v i}$ and the cross-sectional area $P_{s}$, we get a number indicating the so-called uniformity index. The uneven state of dispersed fibers is expressed by the uniformity index approaching zero. Index value approaching 1, on the other hand reveals a uniform state. An example of such expression of dispersion is shown in Figure 5. Calculation of the size of the square assigned to a fiber is embedded in the Eqn (2), which is calculated for each axis in 3D.
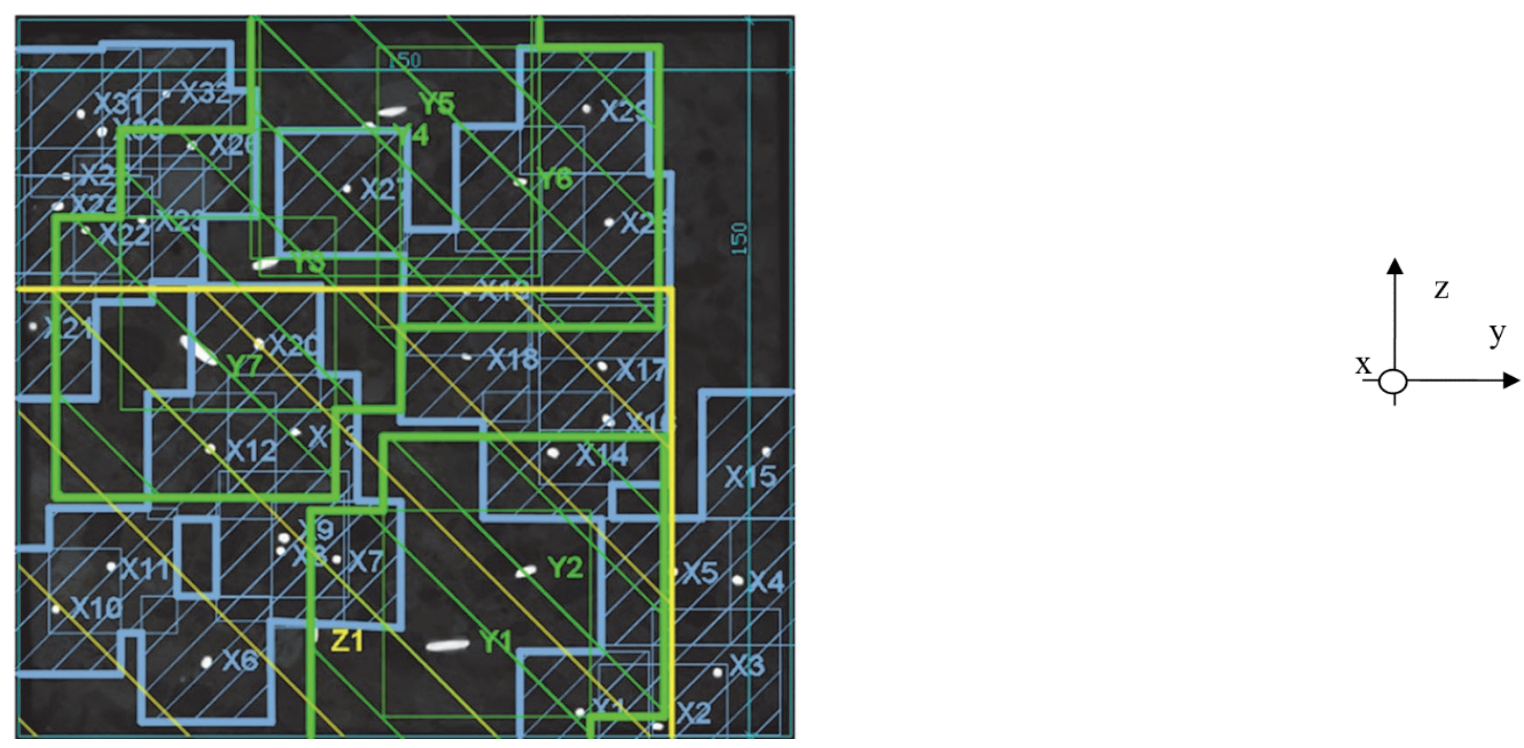

Figure 5. The fiber assigned squares along the axis " $x$ " in blue, the " $y$ " direction green and " $\mathrm{z}$ " yellow colour 
The area of the square assigned to each fiber by-axis direction is then

$$
P_{V}=\frac{P_{s}}{V},
$$

where: $P_{S}$ - represents the image area $(150 \mathrm{~mm} \times 150 \mathrm{~mm})$ $\left(\mathrm{mm}^{2}\right) ; V$ - number of fibers identified by the software (pc); $P_{V}$ - the area of the square associated with the fiber $\left(\mathrm{mm}^{2}\right)$.

Uniformity index (the degree of dispersion) is then calculated as the proportion between the total image area and the amount of overlapping areas.

This calculation is performed for all axes:

$$
i_{r}=\frac{P_{s}}{\sum P_{V}},
$$

where: $i_{r}$ - the uniformity index $(-) ; \sum P_{V}$ - the number of overlapping pads assigned to the fibers $\left(\mathrm{mm}^{2}\right)$.

Exemplary area of overlapping fibers is shown on Figure 6. Drawn are amounts of overlapping areas of the squares.

The total image area is a set of points (pixels). For the mathematical expression in a simple version one-pixel equals to one millimeter. The image area is a set of points $P_{S}=\langle 1 ; 22,500\rangle$, and it is a square with side length of $150 \mathrm{~mm}$. The lower left corner of the image represents the value 1 and point 22,500 is the upper right point of the image. After assigning the squares to the fibers based on their center of gravity each fiber gets an area expressed in coordinates - points. Their range will be registered under the associated axis and the number of identifying fibers as $P_{v} \times 6=<354 ; 1,854>$.

These points count towards the points forming a checkerboard grid. After the allocation of the next square to the fiber adjacent to the preceding one, the pad assigned to that fiber has again an interval registered as: $P_{v} \times 11=$ $<1,487 ; 3,852\rangle$. Points in the intersection will not be labeled for the second time, because they already belong to a group of points forming a square area.

Their entry will be written as a set of points:

$$
P_{V} .6 \cup P_{V} .11=P_{V} .6+P_{V} .11-\left[P_{V} .6 \cap P_{V} .11\right] \text {. }
$$

By gradually adding points from pads assigned to fibers, an overlapping area is created and in the same manner the next table is always added.

An equation is then valid:

$$
P_{V 1} \cup P_{V i}=P_{V 1}+P_{V i}-\left[P_{V 1} \cap P_{V i}\right] \text {, }
$$

where: $P_{v 1}$ represents the square area assigned to the fiber $(-) ; P_{v i}-$ the square area assigned to $i$-th fiber $(-)$.

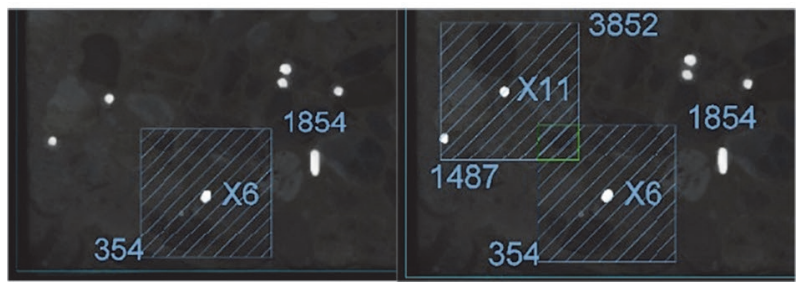

Figure 6. Assigned squares to fibers along the " $\mathrm{x}$ " axis
The relationship and process are repeated. Pads assigned to fibers in an overlapping manner, do not increase the resulting uniformity index, because after the first count the second-time points are not counted anymore.

A similar procedure is used for fibers around each of the three main axes in $3 \mathrm{D}$ space (see Figure 7 ).
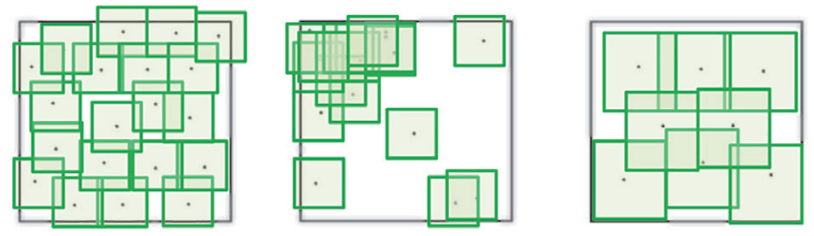

Figure 7. Illustrative placement of fibers on cutting surface. Green colour-image centroid Orange colour-centroid of the fibers

Table 1. Illustrative expression of various types of placement

\begin{tabular}{|l|c|c|c|}
\hline Image & $\begin{array}{c}\text { Fibers } \\
\text { detected in cut } \\
(\mathrm{pc})\end{array}$ & $\begin{array}{c}\text { Fibers } \\
\text { theoretically } \\
\text { estimated }(\mathrm{pc})\end{array}$ & $\begin{array}{c}i_{r} \text { - uniformity } \\
\text { index }(-)\end{array}$ \\
\hline left & 20 & 20 & 0.92 \\
center & 20 & 20 & 0.33 \\
right & 8 & 20 & 0.91 \\
\hline
\end{tabular}

The resulting uniformity indices are calculated in Table 1 . The scan area size is $150 \mathrm{~mm} \times 150 \mathrm{~mm}$. This represents an area of $22,500 \mathrm{~mm}^{2}$. The average uniformity index size amounts to 0.55 (Table 2). The size of the overlapping area was measured in a control manner in the CAD program.

Forecasts of fibers of scored by III. Stereology sentence follows from the length of the fibers inserted into one cubic meter of concrete. Their conversion is indicated in Tables 3 and 4 .

With known data on the fibers we can determine the amount of randomly detected fibers - an estimate of the intersection points.

Table 2. Overlapping areas and calculation of $i_{r}$

\begin{tabular}{|c|c|c|c|}
\hline $\begin{array}{l}\text { Fiber width } D \\
(\mathrm{~mm})\end{array}$ & 1.05 & $L / D$ - Slenderness ratio & 57.20 \\
\hline $\begin{array}{l}\text { Fiber length } L \\
(\mathrm{~mm})\end{array}$ & 60.07 & $\begin{array}{l}L v_{k g}-\text { Fiber length total } \\
\left({\left.\mathrm{m} . \mathrm{kg}^{-1}\right)}\right.\end{array}$ & 150.175 \\
\hline $\begin{array}{l}v_{k g}-\text { Amount } \\
\left(\mathrm{pc} \cdot \mathrm{kg}^{-1}\right)\end{array}$ & 2,500 & 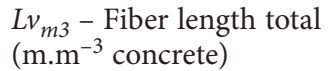 & $4,505.25$ \\
\hline
\end{tabular}

\begin{tabular}{|c|c|c|c|}
\hline Axis & $\begin{array}{c}\text { Overlapped area } \\
P_{v}\left(\mathrm{~mm}^{2}\right)\end{array}$ & $\begin{array}{c}\text { Image area } \\
P_{s}\left(\mathrm{~mm}^{2}\right)\end{array}$ & $\begin{array}{c}i_{r}-\text { uniformity } \\
\text { index }(-)\end{array}$ \\
\hline $\mathrm{x}$ & 13,181 & 22,500 & 0.59 \\
$\mathrm{y}$ & 12,326 & 22,500 & 0.55 \\
$\mathrm{z}$ & 11,729 & 22,500 & 0.52 \\
\hline
\end{tabular}

Table 3. Fiber dimensions, calculation of fiber dosage and statistics 
Table 4. Statistical estimate of cut fibers

\begin{tabular}{|l|c|}
\hline $\begin{array}{l}E(N)-V_{T} \text { amount of cut fibers } \\
\left(\text { pc. } \text { cross-section }^{-1}\right):\end{array}$ & 50.68406 \\
\hline$V-$ number of actually detected fibers $(\mathrm{x}, \mathrm{y}, \mathrm{z})$ & 40 \\
\hline
\end{tabular}

The uniformity index can have the same value in shots with $15 \mathrm{pc}$ of fibers exposed, but also in shots with 57 pieces of fibers. Therefore, the uniformity index should be multiplied by the ratio of identified fibers and fibers theoretically expected. This calculation is then to be done for each axis ( $\mathrm{x}, \mathrm{y}, \mathrm{z})$. The lowest homogeneity is shown on " $\mathrm{z}$ " axis, because it contains the lowest number of fibers in its direction (Table 5).

Table 5. Calculation table of partial and total percentage of the image's uniformity

\begin{tabular}{|c|c|c|c|c|}
\hline Axis & $\begin{array}{c}\text { Number of } \\
\text { estimated } \\
\text { fibers in } \\
\text { image total } \\
E(N)-V_{T} \\
(\mathrm{pc})\end{array}$ & $\begin{array}{c}\text { Estimated } \\
\text { number of } \\
\text { fibers per } \\
\text { axis } V_{T} / 3 \\
(\mathrm{pc})\end{array}$ & $\begin{array}{c}\text { Number } \\
\text { of } \\
\text { detected } \\
\text { fibers per } \\
\text { axis (pc) }\end{array}$ & $\begin{array}{c}i_{r}- \\
\text { uniformity } \\
\text { index (-) }\end{array}$ \\
\hline $\mathrm{x}$ & & 17 & 31 & 0.59 \\
$\mathrm{y}$ & 50 & 17 & 8 & 0.55 \\
$\mathrm{z}$ & & 17 & 1 & 0.52 \\
\hline
\end{tabular}

\subsection{Analysing software}

To search for fibers a specific application has been prepared. The basic application is designed in $\mathrm{C}++$ (Ponikiewski, Gołaszewski 2015). The application architecture is built to utilize external libraries OpenCV. OpenCV is an open-platform library designed for image processing. It is focused on the computer vision and image processing in real-time (Bradski 2000). Graphical application environment is created in the library of the Microsoft Foundation Class Library (MFC), which encapsulates the Windows API in $\mathrm{C}++$ classes, ensuring full compatibility with most Windows platforms. Used technologies ensure scalability of the application and expandability of the new features in the future.

On to the loaded input image selected filters of the OpenCV library are applied. If the input image is large, and it contains dead spots on the edges, the software uses thresholding (image processing depicted in Figure 8). Sub-

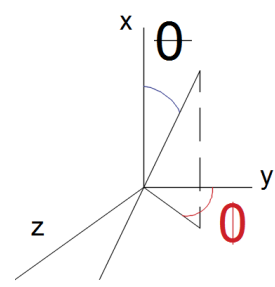

Figure 9. Analysis of cut fiber

sequently contours are searched for, while convexity defects are combined to form one solid object. The result of this step is the cut-out image of the concrete sample. The image of the concrete sample is then processed using morphological reconstruction to eliminate local maximums. Subsequently, methods of erosion and dilation were applied to improve the quality of bright parts. Along with the binary thresholding bright parts were obtained, which in our case represents the found fibers (Žirgulis et al. 2016; Lee et al. 2016; Ponikiewski, Gołaszewski 2015; Eik 2014).

The detection software retrieves the image taken. It will analyze each fiber and by rotation and size assigns it to the relevant axis. The software operates in an " $x$, $y$ " coordinate system, and each detected fiber has coordinates, with which the output information is further processed (Figure 9). It also detects the resulting centroid of all fibers. The created software works in a pixel coordinate system. The square area is expressed by ones in an area labeled with zeros. These ones are not transcribed for the second time and, so they form the overlapping area created by the squares.

Fibers assigned to the axes based on the basic mathematical functions and presented in Ponikiewski and Golaszewski (2012), Žirgulis et al. (2016), Lee et al. (2016) and Eik (2014). Angles concerned are $\theta$ and $\Phi$ - according to the image below (Figure 10).

The fiber dispersion coefficient and uniformity index " $i_{r}$ " is automatically calculated via the following steps:

1) Building specimen, cutting and photographing;

2) Software image processing consists of following steps:

a) Convert the RGB image to a grayscale image;

b) Convert the grayscale image to a binary image based on a set threshold - object detection based on a thresholding algorithm;

c) Divide the binary image into units, i.e., equivalent squares, of which the total number equals the number of fibers $(n)$;
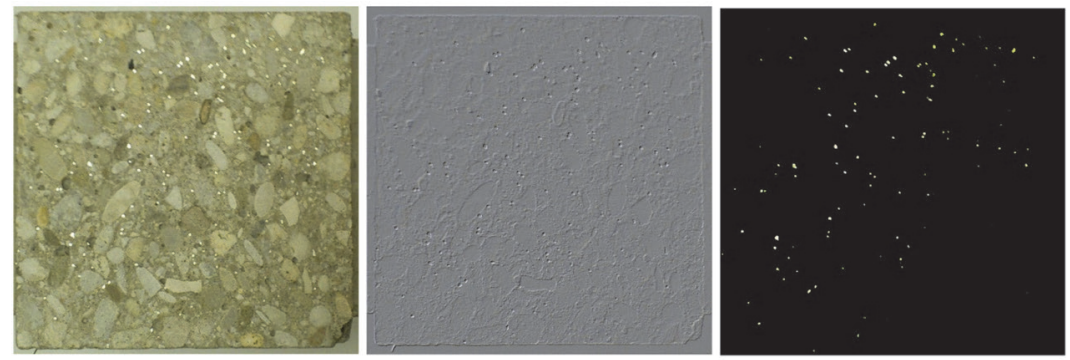

Figure 8. Image processing procedures 


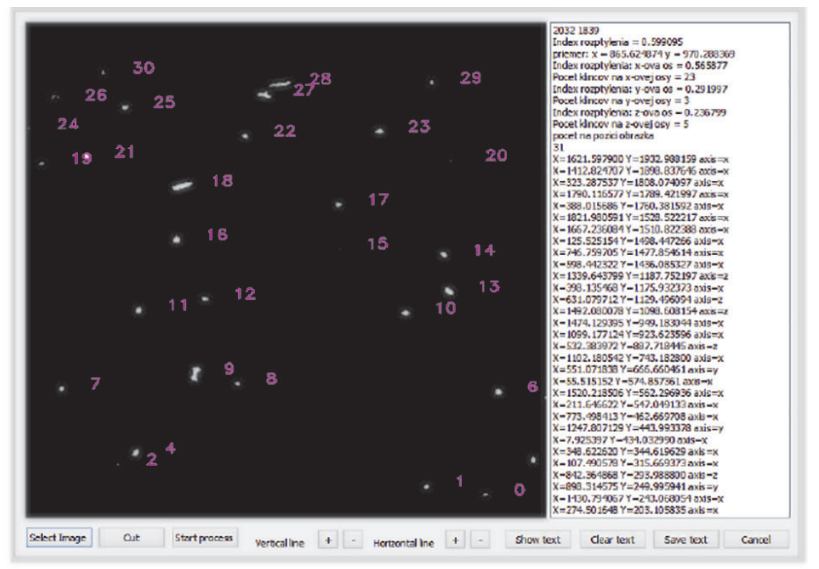

Figure 10. The trimmed image with fibers detected and the output value $i_{r}$

d) Obtain the coordinate data for the centroid of each fiber image;

e) Each fiber is assigned with square area based on the number of fibers. Areas are added together and divided by the detection area. By overlapping of these areas, the sum of the total overlapping area is reduced in comparison with total cross-sectional area. Subsequent dividing of this area, which sums up all areas, by total cross-sectional area leads to number expressing so called uniformity index.

3) Analysis of each axis separately, uniformity evaluation.

\section{Results of the research}

Measurement and the evaluation method show dispersion of fibers. Table 6 records the number of actually detected fibers to individual axes along with the detection area and the uniformity index. The solid line depicts the course of dispersed fibers (Figure 11). It constitutes the number of detected fibers, the number of theoretically estimated fibers and their flat dispersal. The axes $(\mathrm{x}, \mathrm{y}, \mathrm{z})$ are drawn in a different colour. The largest representation of rotated fibers shows routing around the " $\mathrm{x}$ " axis. It is necessary to take software bugs, ill-drawn fibers in cross-section, and with a tolerance of pixels into consideration. Based on the results, the impact of filling and the shape of the casting

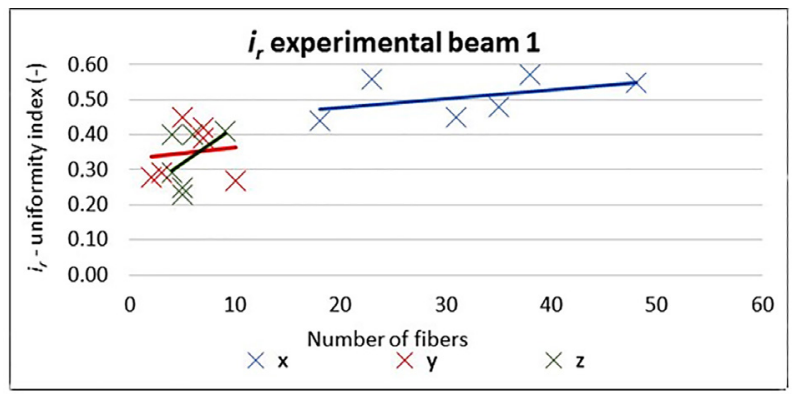

Figure 11. Output chart with $i_{r}$ experimental beam 1 on the resulting fiber orientation can be determined. The expected number of fibers is 50 .

Table 7 presents the amount of fibers detected by the software from cuts performed by core drilling. The " $\mathrm{x}$ " axis perpendicular to the cutting plane and the " $y$ " and " $z$ " axes are parallel to the area of the cut. When analyzing the results of the drill and results detected, higher concentration in the direction of pouring parallel to the direction of concrete flow, can be reported. Mostly in the direction axis " $\mathrm{z}$ " (Figure 12).

Table 6. The output table of the experimental beam sample 1

\begin{tabular}{|c|c|c|c|c|}
\hline \multirow[t]{2}{*}{ Image/cut } & \multirow[t]{2}{*}{ Axis } & \multicolumn{2}{|c|}{$\begin{array}{c}V-\text { Number of fibers } \\
\text { detected }(\mathrm{pc})\end{array}$} & \multirow{2}{*}{$\begin{array}{c}i_{r}-\text { uniformity } \\
\text { index }(-)\end{array}$} \\
\hline & & to axis & Total & \\
\hline \multirow{3}{*}{$1 \mathrm{~B}$} & $\mathrm{x}$ & 23 & \multirow{3}{*}{31} & 0.56 \\
\hline & $\mathrm{y}$ & 3 & & 0.29 \\
\hline & $\mathrm{z}$ & 5 & & 0.23 \\
\hline \multirow{3}{*}{$1 \mathrm{C} ; 1 \mathrm{D}$} & $\mathrm{x}$ & 31 & \multirow{3}{*}{44} & 0.45 \\
\hline & $\mathrm{y}$ & 7 & & 0.42 \\
\hline & $\mathrm{z}$ & 6 & & 0.40 \\
\hline \multirow{3}{*}{$1 \mathrm{E} ; 1 \mathrm{~F}$} & $\mathrm{x}$ & 18 & \multirow{3}{*}{27} & 0.44 \\
\hline & $\mathrm{y}$ & 5 & & 0.45 \\
\hline & $\mathrm{z}$ & 4 & & 0.40 \\
\hline \multirow{3}{*}{$1 \mathrm{G} ; 1 \mathrm{H}$} & $\mathrm{x}$ & 38 & \multirow{3}{*}{54} & 0.57 \\
\hline & $\mathrm{y}$ & 7 & & 0.39 \\
\hline & $\mathrm{z}$ & 9 & & 0.41 \\
\hline \multirow{3}{*}{$1 \mathrm{I} ; 1 \mathrm{~J}$} & $\mathrm{x}$ & 48 & \multirow{3}{*}{63} & 0.55 \\
\hline & $y$ & 10 & & 0.27 \\
\hline & $\mathrm{z}$ & 5 & & 0.25 \\
\hline \multirow{3}{*}{$1 \mathrm{~K}$} & $\mathrm{x}$ & 35 & \multirow{3}{*}{41} & 0.48 \\
\hline & $\mathrm{y}$ & 2 & & 0.28 \\
\hline & $\mathrm{z}$ & 4 & & 0.29 \\
\hline
\end{tabular}

Table 7. The output table of the experimental core drill

\begin{tabular}{|l|c|c|c|c|}
\hline \multirow{2}{*}{ Image/cut } & \multirow{2}{*}{ Axis } & \multicolumn{2}{|c|}{$\begin{array}{r}V-\text { Number of fibers } \\
\text { detected }(\mathrm{pc})\end{array}$} & \multirow{2}{*}{$\begin{array}{c}i_{r}-\text { uniformity } \\
\text { index }(-)\end{array}$} \\
\cline { 3 - 4 } B & & to axis & Total & \\
\hline \multirow{2}{*}{ B } & 8 & & 0.55 \\
& $\mathrm{y}$ & 9 & 33 & 0.42 \\
& $\mathrm{z}$ & 16 & & 0.50 \\
\hline 1C;1D & $\mathrm{x}$ & 10 & & 0.25 \\
& $\mathrm{y}$ & 12 & 39 & 0.64 \\
& $\mathrm{z}$ & 17 & & 0.56 \\
$1 \mathrm{E} ; 1 \mathrm{~F}$ & $\mathrm{x}$ & 5 & & 0.28 \\
& $\mathrm{y}$ & 10 & 33 & 0.51 \\
& $\mathrm{z}$ & 18 & & 0.59 \\
\hline
\end{tabular}




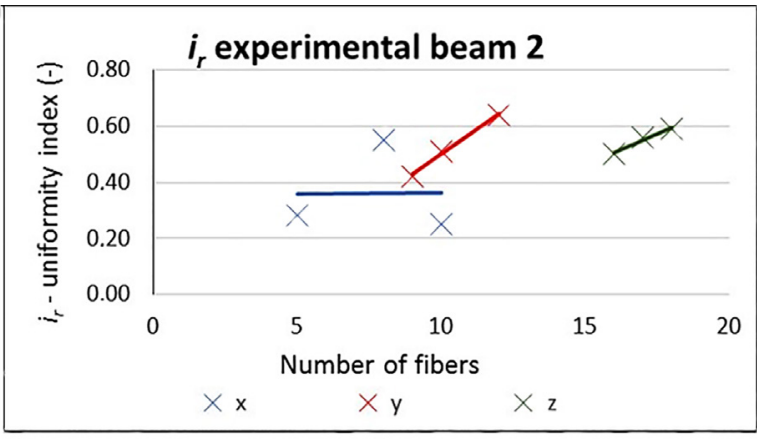

Figure 12. Output chart with $i_{r}$ core drill

\section{Conclusions}

On the basis of our own studies, using our own method and software to analyze the distribution of fibres in concrete, the results were obtained within the selected field of research. The developed computer software allows analysis of the distribution of individual fibers in samples. An image analysis method for automatic segmentation and evaluation of steel fibers was presented.

We proposed a new image analysis technique to estimate the distribution of fiber orientation in a sectional image of fiber-reinforced concrete. The proposed technique is essentially composed of four tasks, i.e., specimen preparation, image acquisition, image processing for fiber detection, and mathematical treatment for calculation of fiber dispersion coefficient. In the development of proposed technique, an enhanced fiber detection algorithm based on categorization, watershed algorithm, and morphological reconstruction are also proposed to enhance the fiberdetection performance.

The proposed technique estimates the distribution of fiber orientation by finding optimal distribution functions matching the measured number of fibers by an image analysis with the theoretical number of fibers calculated from the volume and diameter of the fiber, the area of the sectional image and the assumed fiber distribution.

Confirmed was the orientation of fibres consistent with the direction of the formation of a mixture SFRC. The highest value of fiber in the sections of testing beam was in " $x$ " axis, which is perpendicular to the plane of cut and parallel to the flow of the concrete. We can conclude that most of fibers in beams is oriented in the direction of " $x$ " because fibres are influenced also affected by the test beam walls $\left(i_{r}\right.$ for $x=0.508 ; i_{r}$ for $y=0.35 ; i_{r}$ for $\left.z=0.33\right)$. Three horizontal cuts were performed in case of test with core drill. The highest concentration of fibers was in " $\mathrm{z}$ " axis shown in Figure $4\left(i_{r}\right.$ for $x=0.36 ; i_{r}$ for $y=0.52 ; i_{r}$ for $z=0.55)$.

The presented method and software is the introduction to research on the relationship between the distribution of fibers in concrete elements and the strength parameters.

There was no evidence of fibers placed too close to each other and the formation of so-called "hedgehogs".

Submitted outputs present the uniformity index as data defining the final arrangement and orientation of the fibers. It can also be applied to production of fiber reinforced concrete structures with controlled orientation, where the assumption of acting internal forces is known. It also creates a basis for the development of evaluation software and more detailed expression of decomposition of forces into individual axes. Currently the conducted research is aimed at verifying the possibility of evaluating the images obtained from the CT-Scan device.

\section{References}

Balázs, G. L.; Czoboly, O.; Lublóy, É.; Kapitány, K.; Barsi, Á. 2017. Observation of steel fibres in concrete with computed tomography, Construction and Building Materials 140: 534541. https://doi.org/10.1016/j.conbuildmat.2017.02.114

Barbier, E. 1860. Note sur le problème de l'aiguille et le jeu du joint couvert, Journal de Mathématiques Pures et Appliquées 2(5): 273-286.

Bradski, G. 2000. The OpenCV library [online], [cited 10 March 2018]. Available from Internet: http://www.drdobbs.com/ open-source/the-opencv-library/184404319

Deeb, R.; Karihaloo, B. L.; Kulasegaram, S. 2014. Reorientation of short steel fibres during the flow of self-compacting concrete mix and determination of the fibre orientation factor, Cement and Concrete Research 56: 112-120. https://doi.org/10.1016/j.cemconres.2013.10.002

Dupont, D.; Vandewalle, L. 2005. Distribution of steel fibres in rectangular sections, Cement and Concrete Composites 27(3): 391-398. https://doi.org/10.1016/j.cemconcomp.2004.03.005

Eberhardt, C.; Clarke, A.; Vincent, M.; Giroud, T.; Flouret, S. 2001. Fibre-orientation measurements in short-glass-fibre composites - II: A quantitative error estimate of the $2 \mathrm{~d}$ image analysis technique, Composites Science and Technology 61(13): 1961-1974. https://doi.org/10.1016/S0266-3538(01)00106-3

Eik, M. 2014. Orientation of short steel fibres in concrete: measuring and modelling: $\mathrm{PhD}$ thesis. Faculty of Civil Engineering, Institute of Cybernetics at Tallinn University of Technology, and Aalto University School of Engineering.

Eik, M.; Herrmann, H. 2012. Raytraced images for testing the reconstruction of fibre orientation distributions, Proceedings of the Estonian Academy of Sciences 61(2): 128-136. https://doi.org/10.3176/proc.2012.2.05

EN 14845:2007 Test methods for fibres in concrete - Part 1: Reference concretes. European Standard, 2007.

Ferrara, L.; Bamonte, P.; Caverzan, A.; Musa, A.; Sanal, I. 2012. A comprehensive methodology to test the performance of steel fibre reinforced self-compacting concrete (SFR-SCC), Construction and Building Materials 37: 406-424. https://doi.org/10.1016/j.conbuildmat.2012.07.057

Ferrara, L.; Meda, A. 2006. Relationships between fibre distribution, workability and the mechanical properties of SFRC applied to precast roof elements, Materials and Structures 39(4): 411-420. https://doi.org/10.1617/s11527-005-9017-4

Ferrara, L.; Park, Y. D.; Shah, S. P. 2008. Correlation among fresh state behaviour, fiber dispersion and toughness properties of SFRCs, Journal of Materials in Civil Engineering 20(7). https://doi.org/10.1061/(ASCE)0899-1561(2008)20:7(493)

Gettu, R.; Gardner, D. R.; Saldivar, H.; Barrgán, B. E. 2005. Study of the distribution and orientation of fibers in SFRC specimens, Materials and Structures 38(1): 31-37. https://doi.org/10.1007/BF02480572

Gregorová, V.; Stefunková, Z. 2016. Influence of glass fibres to volume changes in cement composites, Czech Journal of Civil Engineering 2(1): 38-43. 
Grunewald, S.; Walraven, J. C.; Obladen, B.; Zegwaard, J. W.; Langbroek, M.; Nemegeer, D. 2003. Tunnel segments of selfcompacting steel fibre reinforced concrete, in International RILEM Symposium on Selfcompacting Concrete. RILEM Publications SARL, Paris, France, 715-724.

Henry, M.; Darma, I. S.; Sugiyama, T. 2014. Analysis of the effect of heating and recurring on the microstructure of highstrength concrete using X-ray CT, Construction and Building Materials 67(Part A): 37-46.

Kang, S. T.; Lee, B. Y.; Kim, J-K.; Kim, Y. Y. 2011. The effect of fibre distribution characteristics on the flexural strength of steel fibre-reinforced ultra high strength concrete, Construction and Building Materials 25: 2450-2457. https://doi.org/10.1016/j.conbuildmat.2010.11.057

Kang, S-T.; Kim, J.-K. 2012. Numerical simulation of the variation of fiber orientation distribution during flow molding of ultra high performance cementitious composites (UHPCC), Cement and Concrete Composites 34: 208-217. https://doi.org/10.1016/j.cemconcomp.2011.09.015

Katzer, J.; Domski, J. 2012. Quality and mechanical properties of engineered steel fibres used as reinforcement for concrete, Construction and Building Materials 34: 243-248. https://doi.org/10.1016/j.conbuildmat.2012.02.058

Kim, K. Y.; Yun, T. S.; Choo, J.; Kang, D. H.; Shin, H. S. 2012. Determination of air-void parameters of hardened cementbased materials using X-ray computed tomography, Construction and Building Materials 37: 93-101. https://doi.org/10.1016/j.conbuildmat.2012.07.012

Komárková, T. 2016. Design of methodology for non-destructive testing of steel-reinforced-fiber-concrete, Key Engineering Materials 714: 179-185. https://doi.org/10.4028/www.scientific.net/KEM.714.179

Kwon, S. H.; Kang, S.-T.; Lee, B. Y.; Kim, J.-K. 2012. The variation of flow-dependent tensile behavior in radial flow dominant placing of ultra high performance fiber reinforced cementitious composites (UHPFRCC), Construction and Building Materials 33: 109-121. https://doi.org/10.1016/j.conbuildmat.2012.01.006

Lee, B. Y.; Kang, S.-T.; Yun, H.-B.; Kim, Y. Y. 2016. Improved sectional image analysis technique for evaluating fiber orientations in fiber-reinforced cement-based materials, Materials 9(1): 42. https://doi.org/10.3390/ma9010042

Lee, B. Y.; Kim, J. K.; Kim, J. S.; Kim, Y. Y. 2009. Quantitative evaluation technique of Polyvinyl Alcohol (PVA) fiber dispersion in engineered cementitious composites, Cement and Concrete Composites 31: 408-417.

https://doi.org/10.1016/j.cemconcomp.2009.04.002

Lee, J.-H.; Cho, B.; Choi, E. 2017. Flexural capacity of fiber reinforced concrete with a consideration of concrete strength and fiber content, Construction and Building Materials 138: 222 231. http://dx.doi.org/10.1016/j.conbuildmat.2017.01.096

Leone, M.; Centonze, G.; Colonna, D.; Micelli, F.; Aiello, M. A. 2018. Fiber-reinforced concrete with low content of recycled steel fiber: Shear behavior, Construction and Building Materials 161(10): 141-155.

https://doi.org/10.1016/j.conbuildmat.2017.11.101

Liu, J. P.; Li, C. F.; Liu, J. Z.; Cui, G.; Yang, Z. 2013. Study on $3 \mathrm{D}$ spatial distribution of steel fibers in fiber reinforced cementitious composites through micro-CT technique, Construction and Building Materials 48: 656-666. https://doi.org/10.1016/j.conbuildmat.2013.07.052

Martinie, L.; Roussel, N. 2011. Simple tools for fiber orientation prediction in industrial practice, Cement and Concrete
Research 41(10): 993-1000.

https://doi.org/10.1016/j.cemconres.2011.05.008

Mishurova, T.; Rachmatulin, N.; Fontana, P.; Oesch, T.; Sevostianov, I. 2018. Evaluation of the probability density of inhomogeneous fiber orientations by computed tomography and its application to the calculation of the effective properties of a fiber-reinforced composite, International Journal of Engineering Science 122: 14-29.

https://doi.org/10.1016/j.ijengsci.2017.10.002

Mobasher, B.; Stang, H.; Shah, S. 1990. Microcracking in fiber reinforced concrete, Cement and Concrete Research 20(5): 665-676. https://doi.org/10.1016/0008-8846(90)90001-E

Nunes, S.; Pimentel, M.; Carvalho, A. 2016. Non-destructive assessment of fibre content and orientation in UHPFRC layers based on a magnetic method, Cement and Concrete Composites 72: 66-79.

http://dx.doi.org/10.1016/j.cemconcomp.2016.05.024

Nunes, S.; Pimentel, M.; Ribeiro, F.; Milheiro-Oliveira, P.; Carvalho, A. 2017. Estimation of the tensile strength of UHPFRC layers based on non-destructive assessment of the fibre content and orientation, Cement and Concrete Composites 83: 222238. http://dx.doi.org/10.1016/j.cemconcomp.2017.07.019

Poitou, A.; Chinesta, F.; Bernier, G. 2001. Orienting fibers by extrusion in reinforced reactive powder concrete, Journal of Engineering Mechanics 127(6). https://doi.org/10.1061/(ASCE)0733-9399(2001)127:6(593)

Ponikiewski, T.; Golaszewski, J. 2012. The new approach to the study of random distribution of fibres in high performance self-compacting concrete, Cement Wapno Beton 17(3): 165.

Ponikiewski, T.; Gołaszewski, J. 2015. X-ray investigation and modelling of steel fibres In self-compacting concrete, Transactions of the VŠB - Technical University of Ostrava, Civil Engineering Series 15(2). https://doi.org/10.1515/tvsb-2015-0020

Ponikiewski, T.; Gołaszewski, J.; Rudzki, M.; Bugdol, M. 2015. Determination of steel fibres distribution in self-compacting concrete beams using X-ray computed tomography, Archives of Civil and Mechanical Engineering 15(2): 558-568. https://doi.org/10.1016/j.acme.2014.08.008

Ponikiewski, T.; Katzer, J.; Bugdol, M.; Rudzki, M. 2015. X-ray computed tomography harnessed to determine $3 \mathrm{D}$ spacing of steel fibres in self compacting concrete (SCC) slabs, Construction and Building Materials 74: 102-108. https://doi.org/10.1016/j.conbuildmat.2014.10.024

Roussel, N.; Geiker, M. R.; Dufour, F.; Thrane, L. N.; Szabo, P. 2007. Computational modeling of concrete flow: general overview, Cement and Concrete Research 37: 1298-1307. https://doi.org/10.1016/j.cemconres.2007.06.007

Rudzki, M.; Bugdol, M.; Ponikiewski, T. 2013. Determination of steel fibers orientation in SCC using computed tomography and digital image analysis methods, Cement Wapno Beton 80: 257-263.

Şanal, İ.; Ozyurt, N. 2013. To what extent does the fiber orientation affect mechanical performance?, Construction and Building Materials 44: 671-681. https://doi.org/10.1016/j.conbuildmat.2013.03.079

Špak, M.; Kozlovská, M.; Struková, Z.; Bašková, R. 2016. Comparison of conventional and advanced concrete technologies in terms of construction efficiency, Advances in Materials Science and Engineering. Article ID 1903729. https://doi.org/10.1155/2016/1903729

Stähli, P. 2008. Ultra-fluid oriented hybrid-fibre-concrete: Dissertation thesis. Swiss Federal Institute of Technology Zurich, Switzerland. 
Stähli, P.; van Mier, J. G. M. 2007. Manufacturing, fibre anisotropy and fracture of hybrid fibre concrete, Engineering Fracture Mechanics 74(1-2): 223-242. https://doi.org/10.1016/j.engfracmech.2006.01.028

Stroeven, P.; Guo, Z. 2008. Distribution and orientation of fibers in the perspective of concrete's mechanical properties, fibre reinforced concrete: Design and applications, in Proceedings of the $7^{\text {th }}$ RILEM International Symposium, Paris, France, $145-154$.

Švec, O.; Žirgulis, G.; Bolander, J. E.; Stang, H. 2014. Influence of formwork surface on the orientation of steel fibres within self-compacting concrete and on the mechanical properties of cast structural elements, Cement and Concrete Composites 50: 60-72. https://doi.org/10.1016/j.cemconcomp.2013.12.002

Svoboda, P.; Doležal, J. 2008. Výroba a kladenie čerstvého drôtikového betónu na priemyselné podlahy, Stavebné materiály 4(5): 46-48.

The fib model code for concrete structures. Ernst \& Sohn, 2013.

Tosun-Felekoğlu, K.; Felekoğlu, B.; Ranade, R.; Lee, B. Y.; $\mathrm{Li}, \mathrm{V}$. C. 2014. The role of flaw size and fiber distribution on tensile ductility of PVA-ECC, Composites Part B: Engineering 56: $536-545$. https://doi.org/10.1016/j.compositesb.2013.08.089

Wang, R.; Gao, X.; Zhang, J.; Han, G. 2018. Spatial distribution of steel fibers and air bubbles in UHPC cylinder determined by X-ray CT method, Construction and Building Materials 160: 39-47. https://doi.org/10.1016/j.conbuildmat.2017.11.030

Wang, R; Gao, X.; Huang, H. 2017. Influence of rheological properties of cement mortar on steel fiber distribution in UHPC, Construction and Building Materials 144: 65-73. https://doi.org/10.1016/j.conbuildmat.2017.03.173

Wong, R. C. K.; Chau, K. T. 2005. Estimation of air void and aggregate spatial distributions in concrete under uniaxial compression using computer tomography scanning, Cement and Concrete Research 35(8): 1566-1576. https://doi.org/10.1016/j.cemconres.2004.08.016

Yang, C. J.; Jin, L. B.; Chen, D. C.; Qi, J. P. 2013. Practical measurement for steel fiber distribution of the SFRC beams, Applied Mechanics and Materials 256-259: 840-843. https:// doi.org/10.4028/www.scientific.net/AMM.256-259.840

Yong-zhi, L. 2000. Deutscher Ausschuss für Stahlbeton im DIN Deutsches Institut für Normung e.V. 494DAfStb-Heft 494. Tragverhalten von Stahlfaserbeton. Beuth Verlag GmbH, Berlin.

Zhu, Y. T.; Blumenthal, W. R.; Lowe, T. C. 1997. Determination of non-symmetric 3-D fiber orientation distribution and average fiber length in short-fiber composites, Journal of Composite Materials 31(13): 1287-1301. https://doi.org/10.1177/002199839703101302

Žirgulis, G.; Švec, O.; Sarmiento, E. V.; Geiker, M. R.; Cwirzen, A.; Kanstad, T. 2016. Importance of quantification of steel fibre orientation for residual flexural tensile strength in FRC, Materials and Structures 49: 3861-3877. https://doi.org/10.1617/s11527-015-0759-3 